\title{
Eco-friendly Technologies for Physical and Chemical Recycling of PVC-Related Wasteful Resources
}

\author{
Hyoungsan Kye ${ }^{1}$, Sejong Han ${ }^{2}$, Jaemyung $\mathrm{Han}^{2}$, Sukwon Hong ${ }^{3}$, Donghyun Lee ${ }^{4}$ and Jongwook Bae ${ }^{4}$ \\ 1. Department of Applied Chemical Engineering, Mok Won University, Daejeon 35349, Korea \\ 2. Sunjin Concrete Co. Ltd., Buyeo, Chungnam 33175, Korea \\ 3. PPI Pyunghwa Co. Ltd., Hwaseong, Kyunggi 18574, Korea \\ 4. School of Chemical Engineering, Sung Kyun Kwan University, Suwon 16419, Korea
}

\begin{abstract}
The aim of this study is to enhance the recycled PVC (polyvinyl chloride) related material property by formulation technology and develop the recycling product processing technology furthermore develop the chemical recycling technology for last stage of PVC wastes. The formulation technology is composed of pre-treatment (crushing, separation etc.) and post-treatment (material ratio, additives, stabilizer etc.) to enhance the recyclate property. The formulation for recycled PVC by application basis and processing technology is applied to produce the structural product for civil and construction application such as pipe fittings and water drainage cap for environmental waterway. Also chemical recycling technology for end life PVC scrap which causes environmental pollution by incineration or landfill is studied for producing hydrocarbon and hydrogen chloride for VCM.
\end{abstract}

Key words: Eco-friendly technology, mechanical recycling, chemical recycling, dehydrochlorination.

\section{Introduction}

Ever since the first industrial scale production of synthetic polymers (plastics) took place in the 1940s, the production, consumption and waste generation rate of PSW (plastic solid waste) has increased considerably. Thus, PSW recycling has been a focus of many researchers in the past few decades. Such research is also driven by changes in regulatory and environmental issues. Plastics are used in our daily lives in a number of applications, from greenhouses, mulches, coating and wiring, to packaging, films, covers, bags and containers. It is only reasonable to find a considerable amount of PSW in the final stream of MSW (municipal solid waste) [1, 2]. PVC (polyvinyl chloride) is one of the most widely used polymers in the world. The polymer was one of the first modern plastic materials to be discovered. Although first synthesized in the laboratory in the 19th century, commercial development of the polymer

Corresponding author: Hyoungsan Kye, Ph.D., professor, research fields: polymer processing, polymer recycle. commenced in the mid-1920s and saw a dramatic growth during the 1950s. Today, about 37 million tons of PVC is produced worldwide. PVC is produced 900,000 tons in Korea and widely used in the field of civil and construction application. Low cost, excellent property make PVC's wide acceptance in the market. As a consequence, post-consumer PVC waste amount increases with over durability life product and dumped from reconstruction housing development. It was commonly known the PVC waste causes environmental pollution when treat inadequately such as landfill, incineration and so on. So many researches were performed to find effective treatment method [3, 4] but there were no particular alternatives than re-use and landfill.

PVC resin is one of the typical resins which needs various kinds of additives to control the property for each application. The different end-use wastes were mixed together during the collecting process, one facing the difficulties to recycle waste scrap. Currently most widely recycled end use products were pipe and fittings, profiles and flooring product in Korea. These 
scraps were easy to collect and have simple formulation so it is relatively easy to recycle. As a result many companies produce lower grade products using these post-consumer PVC scrap. There were no specific recycling method for PVC composite with other polymers, soft PVC product such as PVC films and durability life overdue products were difficult to collect and facing difficulties to recycle due to various kinds of additives are used. So these wastes are landfill or incinerate in most cases. Recently a research for using low grade PVC waste as an RPF (refused plastic fuel) for furnace, but it stopped for low economic feasibility.

In Europe, 150,000 tons of post-consumer PVC waste was recycled in 2007 . In order to achieve the demanding target of 800,000 tons/year recycled by 2020, Vinyl Plus tries to develop innovative technologies. Within this target is a contribution of 100,000 tons from "more difficult to recycle" PVC waste [5].

Japan government strongly forced to recycle plastic waste by basic law for establishing the recycling-based society and waste management and public cleansing law and so on [6]. As a result $61 \%$ of PVC pipes and $70 \%$ of agricultural films were recycled on the floor covering application, low quality waste such as deteriorated films and wall covers were chemically recycled through 19 large size chemical recycling plants, but start to investigate new physical recycling process because of energy recovery processing cost problems.

850,000 tons of PVC were used in Korea annually, 340,000 tons for films, 115,000 tons for pipe and fittings, 115,000 tons for wire and cable covering, 15,000 tons for electrical components, 134,000 tons for window profiles and 120,000 tons of PVC were used for other usage. The collected post-consumer PVC was 105,000 tons and 30,000 tons of PVC were imported from foreign countries and recycled to low quality hose and pipes. The mechanical recycling of post-consumer PVC was very business-like but energy recovery and feedstock for PVC were dull and chemical recycle is not studied ever before because of low economic feasibility [7].

In this study, mechanical recycling is performed for dumped PVC waste to develop a total recycling system and try to develop chemical recycling technology for low quality PVC wastes. The basic mechanical properties and collecting forms and composition investigated and analyzed. Also basic catalyst study and PVC conversion ratio with catalysts were investigated.

\section{Experimental}

\subsection{Material}

Three different class of post-consumer PVC wastes: RC (Rigid composite scrap), PC (Pipe scrap), CC (Cloth collar scrap), were used in this study. The RC consists of various post-consumer rigid PVC scraps which were not identified the origins and usage, PC was mainly collected from the pressure and non-pressure pipes, $\mathrm{CC}$ was recycled from $\mathrm{Y}$-shirt collar scrap. The characteristics of materials used in this study are presented in Table 1. A virgin PVC resin was used for comparison purposes.

\subsection{Specimen Preparation}

The high impact resistant pressure pipe formulation is adopted for post-consumer PVC scrap characterization. The formulations consist of base resin $100 \mathrm{phr}$, stabilizer $5 \mathrm{phr}$, impact modifier $8 \mathrm{phr}$, processing lubricant $2 \mathrm{phr}$, filler $2 \mathrm{phr}$.

The compounds were mixed with $120{ }^{\circ} \mathrm{C}, 2,100$ rpm by Henschel mixer. The mixtures were processed into sheet by mixing roll with 6 minutes and 4 layers of sheet were laminated onto $3 \mathrm{~mm}$ thick sheet for preparing mechanical specimens by mold press, and the processing conditions are shown in Table 2, and the specimens prepared are shown in Fig. 1.

\subsection{Mechanical Properties of Recycled Scrap}

The mechanical properties of scrap materials are compared by virgin specimen. The tensile strength, 
Table 1 The characteristics of materials used in this study.

\begin{tabular}{llll}
\hline Item & Contents & Type & Source \\
\hline RC & Rigid composite PVC & Scrap powder & Nam Yang \\
PC & Pipe & Scrap powder & PPI \\
CC & Cloth collar & Scrap powder & Nam Yang \\
P-1000 & Pure resin & Fine powder & Hanhwa Chemical \\
\hline
\end{tabular}

Table 2 Sample preparation process condition.

\begin{tabular}{ll}
\hline Item & Condition \\
\hline Henschel mixer & $2,100 \mathrm{rpm}, 120{ }^{\circ} \mathrm{C}$ \\
Mixing roll & 6 minute, $190^{\circ} \mathrm{C}$ \\
Mold press & $3 \mathrm{~mm}, 195^{\circ} \mathrm{C}$ \\
\hline
\end{tabular}

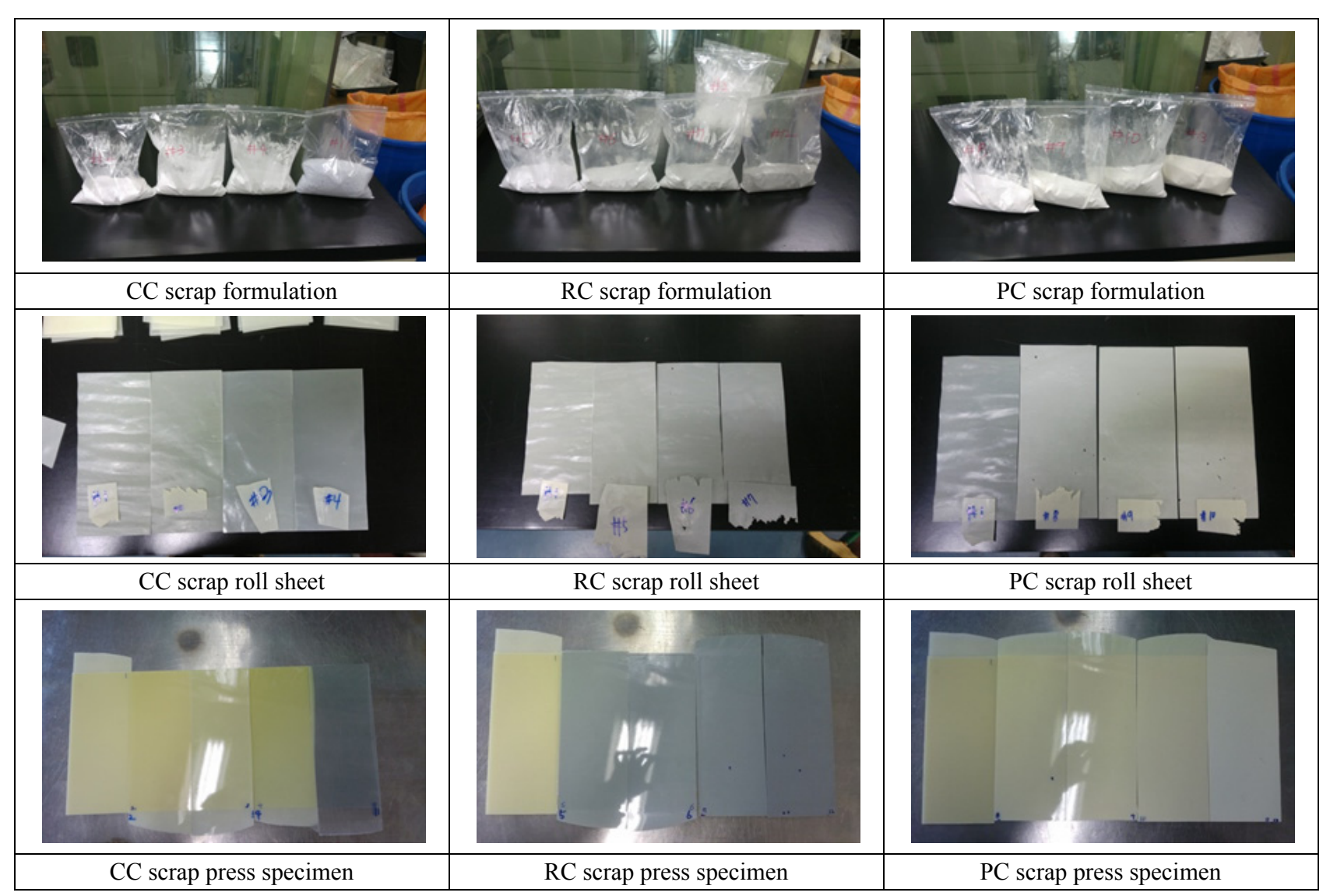

Fig. 1 The post-consumer PVC scrap formulation and specimen preparation.

VICAT and IZOD impact resistance were measured by the Korea Standard (KS) M 3401 which specifies rigid pressure pipe specification. The tensile mechanical properties of the specimen we prepared were measured using a Testometric's Micro 350 tensile tester. The testing procedures were carried out according to ASTM D 638. The specimen was fixed using a compressed air grip. Across-head speed of
$12.5 \mathrm{~mm} / \mathrm{min}$ with $1,000 \mathrm{kgf}$ load cell was used in this experiment. IZOD impact properties were measured by Daekyung's DTI-602 IZOD impact tester with $2 \mathrm{lb}$ IZOD by ASTM D 256. The IZOD notch was made by Kibae's model KPM-080 notch cutter with feed speed of 25 and cutter speed of 55. Tensile and IZOD impact specimens were dried in a convection drying oven at $80^{\circ} \mathrm{C}$ for 24 hours. 


\section{Result and Discussion}

\subsection{Mechanical Properties of PVC Scrap}

The mechanical properties of recycled scrap specimen compared with virgin PVC (P-1000) specimen. Tensile strength, VICT softening temperature and IZOD impact properties were measured by KS M 3401, and the results were summarized in Table 3.

As shown in Table 3, the VICAT temperature of three different scraps shows no tendency and shows no significant differences. Impact resistance of virgin PVC shows $47.9 \mathrm{~kg} \cdot \mathrm{cm} / \mathrm{cm}$ but the CC shows $20.1 \mathrm{~kg} \cdot \mathrm{cm} / \mathrm{cm}$, which are $41 \%$ of virgin $\mathrm{PVC}, \mathrm{PC}$ and $\mathrm{RC}$ shows $13.3 \mathrm{~kg} \cdot \mathrm{cm} / \mathrm{cm}, 5.7 \mathrm{~kg} \cdot \mathrm{cm} / \mathrm{cm}$ in sequence. Which were $27 \%$ and $12 \%$ of virgin PVC's impact resistance. Tensile strength shows same tendency with IZOD. Tensile strength of SC shows lowest value among the specimen and this result mainly caused by the composition of SC. SC scrap consists of several different end used rigid PVC recycled materials. $\mathrm{CC}$ scrap shows much better mechanical properties among the specimen especially on the impact resistance, we guess the $\mathrm{CC}$ consists of one source waste scrap also certain amount of impact modifier already exist for former usage.

\subsection{Mechanical Properties of Post-consumer PVC Scrap with Scrap Ratio}

To investigate the mechanical property variation with the amount of scrap ratio, we compound virgin material with three different scraps of $10,30,50 \mathrm{phr}$ by base formulation. The results were shown in Tables 4-6 and Figs. 2-4.

\subsubsection{Scrap}

As shown in Table 4 and Fig. 2, the impact resistance and tensile strength decreases with increasing scrap ratio. But the impact resistance and tensile strength of $\mathrm{CC}$ compound itself shows highest among the other post-consumer PVC scraps, the decreasing value gaps were lowest.

\subsubsection{RC Scrap}

As shown in Table 5 and Fig. 3, the 10, 30, $50 \mathrm{phr}$ RC scrap were mixed with virgin material, impact resistance dropped sharply than virgin specimen. And impact resistance decreases with $\mathrm{RC}$ ratio increase. This means the basic property of RC scrap is lower than virgin material so $\mathrm{RC}$ affects to decrease mechanical properties of virgin material. Same tendency was shown for the tensile strength. But no significant difference is shown for VICAT.

\subsubsection{PC Scrap}

As shown in Table 6 and Fig. 4, impact resistance of PC scrap decreases with increasing scrap ratio, but the amount of decreased value gaps were less than $\mathrm{CC}$ and RC compound, same tendency were shown for VICAT and tensile strength properties. These phenomena which were caused by PC scraps were collected from pipe application, so basic property is quite similar than RC scrap.

Table 3 Mechanical properties of post-consumer PVC scrap.

\begin{tabular}{lllll}
\hline Item & P-1000 & CC scrap & RC scrap & PC scrap \\
\hline Base resin content & 100 & 100 & 100 & 100 \\
IZOD $(\mathrm{kg} \cdot \mathrm{cm} / \mathrm{cm})$ & 47.9 & 20.1 & 5.7 & 13.3 \\
VICAT $\left({ }^{\circ} \mathrm{C}, 5 \mathrm{~kg}\right)$ & 84.4 & 62.8 & 83.9 & 97.2 \\
Tensile strength $\left(\mathrm{kg}_{\mathrm{f}} / \mathrm{cm}^{2}\right)$ & 532 & 495 & 305 & 490 \\
\hline
\end{tabular}

Table 4 Mechanical properties of CC compound with scrap ratio.

\begin{tabular}{lllll}
\hline Item & P-1000 & CC scrap & & CC-3 \\
\cline { 3 - 5 } & & CC-1 & CC-2 & 100 \\
\hline Base recipe & 100 & 100 & 100 & 50 \\
Scrap ratio & 0 & 10 & 30 & 42.6 \\
IZOD $(\mathrm{kg} \cdot \mathrm{cm} / \mathrm{cm})$ & 47.9 & 45.1 & 43.2 & 77.4 \\
VICAT $\left({ }^{\circ} \mathrm{C}, 5 \mathrm{~kg}\right)$ & 84.4 & 82.6 & 79.2 & 454 \\
Tensile strength $\left(\mathrm{kg}_{\mathrm{f}} / \mathrm{cm}^{2}\right)$ & 532 & 517 & 492 & \\
\hline
\end{tabular}


Table 5 Mechanical properties of RC compound with scrap ratio.

\begin{tabular}{lllll}
\hline Item & P-1000 & RC scrap & & RC-3 \\
\cline { 3 - 5 } & & RC-1 & RC-2 & 100 \\
\hline Base recipe & 100 & 100 & 100 & 50 \\
Scrap ratio & 0 & 10 & 30 & 10.9 \\
IZOD $(\mathrm{kg} \cdot \mathrm{cm} / \mathrm{cm})$ & 47.9 & 20.3 & 17.9 & 84.3 \\
VICAT $\left({ }^{\circ} \mathrm{C}, 5 \mathrm{~kg}\right)$ & 84.4 & 84.3 & 83.8 & 373 \\
Tensile strength $\left(\mathrm{kg}_{\mathrm{f}} / \mathrm{cm}^{2}\right)$ & 532 & 414 & 396 & \\
\hline
\end{tabular}

Table 6 Mechanical properties of PC compound with scrap ratio.

\begin{tabular}{lllll}
\hline \multirow{2}{*}{ Item } & P-1000 & PC scrap & & PC-3 \\
\cline { 3 - 5 } & & PC-1 & PC-2 & 100 \\
Base recipe & 100 & 100 & 100 & 50 \\
Scrap ratio & 0 & 10 & 30 & 23.6 \\
IZOD $(\mathrm{kg} \cdot \mathrm{cm} / \mathrm{cm})$ & 47.9 & 29.1 & 24.9 & 85.4 \\
VICAT $\left({ }^{\circ} \mathrm{C}, 5 \mathrm{~kg}\right)$ & 84.4 & 84.7 & 84.7 & 506 \\
Tensile strength $\left(\mathrm{kg}_{\mathrm{f}} / \mathrm{cm}^{2}\right)$ & 532 & 506 & 509 & \\
\hline
\end{tabular}

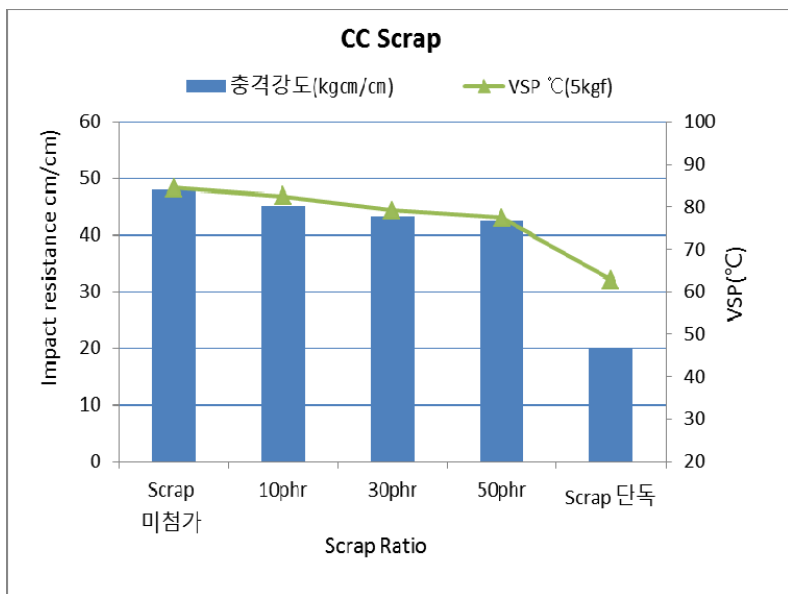

Fig. 2 The overall mechanical properties of CC compound with scrap ratio.

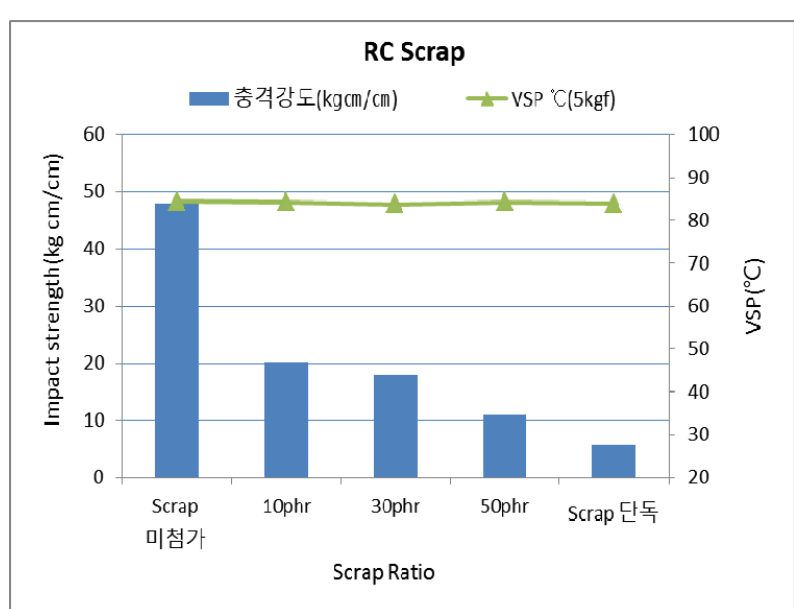

Fig. 3 The overall mechanical properties of RC compound with scrap ratio.



Fig. 4 The overall mechanical properties of PC compound with scrap ratio.

\subsection{Physical Recycling Application of Post-consumer PVC Waste Scrap}

Based on the comparison test result, impact resistance of waste compounds decreases with increasing scrap ratio. Impact resistance of $\mathrm{CC}$ compound shows highest among the other scrap compound and RC and PC scrap's impact resistance were low. As a result, their impact resistance dropped drastically with increasing scrap ratio. Tensile strength of scrap shows decreasing tendency with increasing scrap ratio, but the VICT temperature shows no specific tendency with ratio and scrap. 


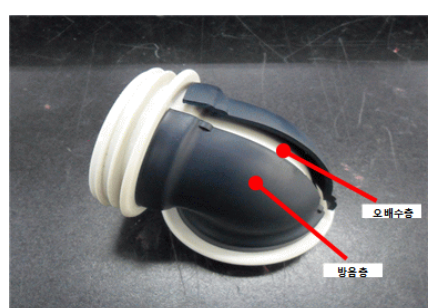

Fig. 5 A pipe fitting outer layer made by post-consumer CC compound.

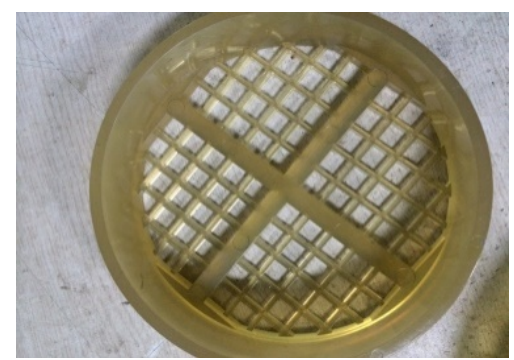

Fig. 6 A conduit cap made by post-consumer PC compound.

To utilize the PVC scrap as a useful resource, we adopt the mechanical test result of several compounds to produce civil application. Some of the application is shown in Figs. 5 and 6.

\section{Chemical Recycle}

Basic chemical recycling investigations for low quality PVC waste were performed. A hydrochloric acid was recovered by the dehydrochlorination reaction and the catalyst system study was investigated.

\subsection{Reaction Catalyst System}

Ionic liquid $\quad\{[\mathrm{Bmim}] \mathrm{Cl}$ (1-butyl-3-methylimidazolium chloride) $\}$ and PEG were chosen for a solvent for dehydrochlorination reaction. Virgin PVC is used to find a reaction condition, such as reaction temperature and amount of catalyst and so on. The FT-IR spectrums of carbon double bond on the titration solution after dehydrochlorination reaction completed were shown in Fig. 7.

In addition, $\mathrm{MgO}$ and $\mathrm{CaO}$ adsorption agent were used to collect $\mathrm{HCl}$ during the simultaneous (dehydrochlorination + adsorption) reaction. The results were shown in Fig. 8, the activity of $\mathrm{CaO}$ is better than $\mathrm{MgO}$ and FT-IR spectrum shows carbon-carbon double bond were created and XRD result shows $\mathrm{CaO}$ and $\mathrm{MgO}$ maintain its structure. So adsorption reaction (2) proceeds faster than chlorination reaction (1) on the (dehydrochlorination + adsorption).

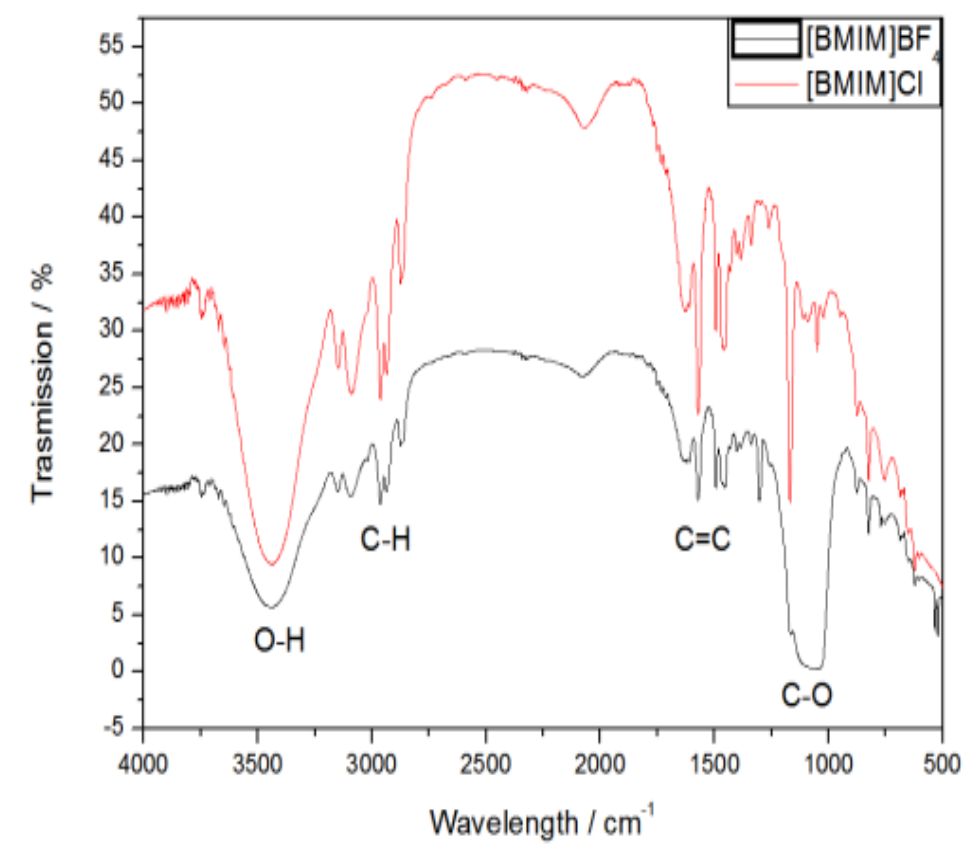

Fig.7 FT-IR result to confirm $\mathrm{C}=\mathrm{C}$ bond result from dehydrochlorination. 


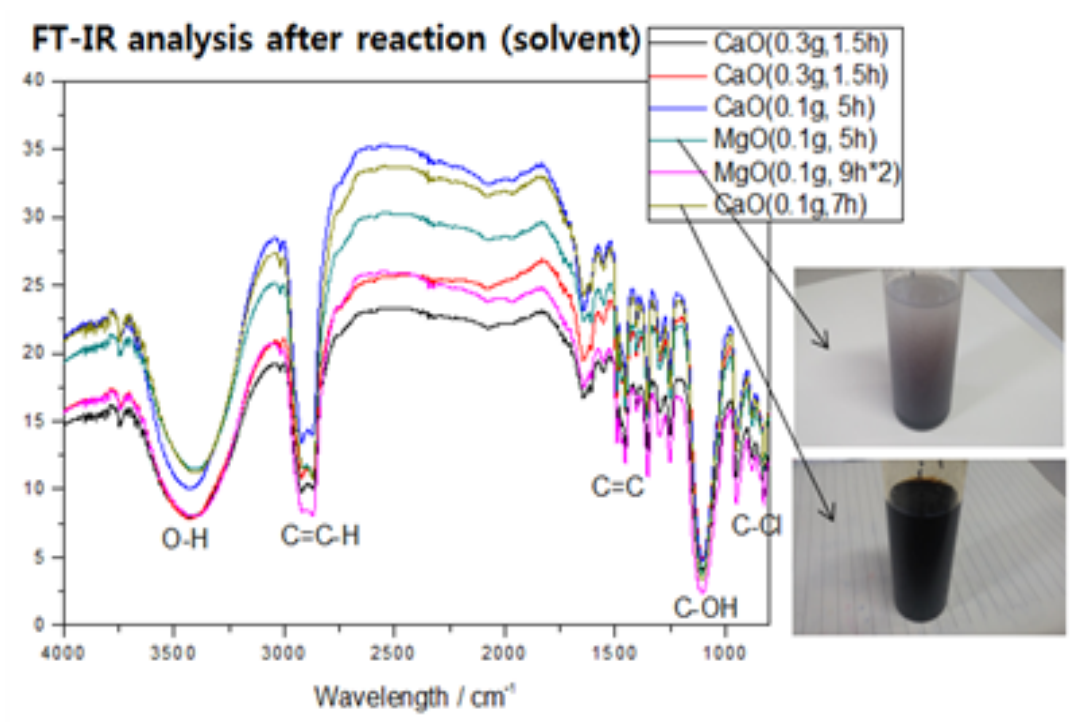

XRD analysis after reaction

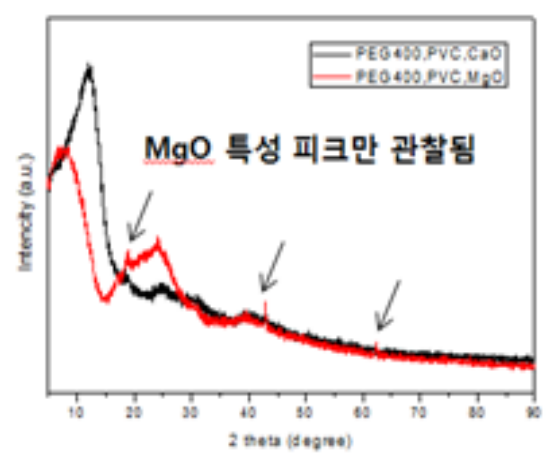

Fig. 8 FT-IRand XRD result for (dehydrochlorination+ adsorption) reaction.

(1) $\mathrm{MgO}($ or $\mathrm{CaO})+2 \mathrm{HCl} \rightarrow \mathrm{MgCl}_{2}\left(\right.$ or $\left.\mathrm{CaCl}_{2}\right)+$ $\mathrm{H}_{2} \mathrm{O}$ (high temperature chlorination reaction);

(2) $\mathrm{MgO}($ or $\mathrm{CaO})+\mathrm{xHCl} \rightarrow \mathrm{MgO} \cdot \mathrm{xHCl}$ (or $\mathrm{CaO} \cdot \mathrm{xHCl})$ (low temperature adsorption reaction).

In case of simultaneous use of PEG 400 and ionic liquid $([\mathrm{Bmin}] \mathrm{Cl})$ for dehydrochlorination reaction for post-consumer low quality PVC waste, $80 \%$ of reaction conversion was achieved. If we use metal oxide adsorbent with above mentioned solvent, then over $88 \%$ of reaction conversion is achieved.

\section{Conclusion}

The mechanical properties of three different post-consumer PVC waste from different end-use applications mechanical properties with their scrap ratio were investigated. Also basic reaction conditions for chemical recycling of low quality post-consumer PVC waste were studied.

(1) VICAT softening temperature of post-consumer PVC is lower than virgin resin but it shows not too low and no specific tendency compared with virgin PVC. Impact resistance and tensile strength were in the order of $\mathrm{CC}>\mathrm{PC}>\mathrm{RC}$.

(2) Impact resistance of $\mathrm{CC}, \mathrm{PC}$ and $\mathrm{RC}$ compound decreased with increasing scrap ratio. The $\mathrm{CC}$ compound has highest impact resistance and value gap deviation is much lower than the other compounds.
The decreasing value deviation of $\mathrm{RC}$ and $\mathrm{PC}$ shows big for impact resistance with increasing scrap ratio.

(3) CC, RC and PC compound show no specific tendency of VICAT softening temperature.

(4) When PEG 400 solvent and ionic liquids $\left([\mathrm{Bmim}] \mathrm{Cl}\right.$ and $\left[\mathrm{Bmim} \mathrm{BF}_{4}\right)$ with metal oxide $(\mathrm{CaO})$ were used for chemical reaction, the conversion rate increased up to $88 \%$. Also PEG400 solvent with $[\mathrm{Bmim}] \mathrm{Cl}$ were used and metal oxides as adsorbent leads dehydrochlorination reaction prevailed. As a result the conversion increased. Further $\mathrm{MgO}$ (or $\mathrm{CaO}$ ) $+\mathrm{xHCl} \rightarrow \mathrm{MgO} \cdot \mathrm{xHCl}$ (or $\mathrm{CaO} \cdot \mathrm{xHCl}$ ) reaction proceeds dominantly to enhance the PVC conversion.

\section{Acknowledgement}

This study was supported by the R\&D Center for Valuable Recycling (Global-Top Environmental Technology Development Program) funded by the Ministry of Environment (Project No. GT-14-C-01-038-0).

\section{References}

[1] Lee, J. et al. 2002. "Recycling Technology of PVC Waste." Polym. Sci. Technol. 13 (3): 332-41.

[2] Al-Salem, S. M., Lettieri, P., and Baeyens, J. 2009. "Recycling and Recovery Routes of Solid Waste (PSW): A Review." Waste Manag. 29: 2625-43.

[3] Hopewell, J., Dvorak, R., and Kosior, E. 2009. "Plastics 
Recycling: Challenges and Opportunities.” Phil. Trans. R. Soc. B 364: 2115-26.

[4] Vinyl Plus. 2011. "The Voluntary Commitment of the European PVC Industry."

[5] Leveson, I. 2007. "Vinyl: 2020 Ten Years Later." World Vinyl Forum III, September.
[6] Vinyl Plus. 2014. "Vinyl plus PVC Recycling Technologies."

[7] Seki, S., Osakada, F., and Yoshooka, T. 2014. "Developments in an Industry-Led R\&D Program for Recycling PVC Products in Japan." J. Mat. Cycles \& Waste Manag. 16 (3): 332-41. 